\title{
Visible-Light-Induced Metal-Free Trifluoromethylselenolation of Electron-Rich Heteroarenes using the Nucleophilic $\left[\mathrm{Me}_{4} \mathrm{~N}\right]\left[\mathrm{SeCF}_{3}\right]$ Reagent
}

\author{
Arnaud De Zordo-Banliat, ${ }^{[a]}$ Lucas Barthélémy, ${ }^{[b]}$ Flavien Bourdreux, ${ }^{[a]}$ Béatrice Tuccio, ${ }^{[b]}$ Guillaume \\ Dagousset, ${ }^{*}[\mathrm{a}]$ Bruce Pégot, ${ }^{*[a]}$ and Emmanuel Magnier ${ }^{*}[\mathrm{a}]$
}

\begin{abstract}
A metal-free visible-light-promoted regioselective trifluoromethylselenolation of electron-rich heteroarenes has been developed via $\mathrm{C}-\mathrm{H}$ functionalization. This eco-friendly, atomeconomical, and easy-to-operate protocol provides direct access to a wide range of functionalized $\mathrm{SeCF}_{3}$-containing heteroarenes in high yields, and is amenable to continuous flow techniques. A radical mechanism was supported by EPR experiments.
\end{abstract}

Organofluorine molecules have attracted continuous interest due to the specific properties of this halogen. These fluorinated compounds have found many applications in various areas, from life sciences to materials science. ${ }^{[1]}$ More recently, it has been shown that the association of a $\mathrm{CF}_{3}$ moiety with a heteroatom (such as oxygen, sulfur, or selenium) can deeply modulate these physicochemical and biological properties. ${ }^{[2]}$ Amongst these new emergent fluorinated moieties, the $\mathrm{SeCF}_{3}$ group has probably been the least studied, but a clear resurgence of the appeal for this group recently appeared in the literature. Selenoproteins are indeed useful endogenous molecules, and some organoselenium compounds have interesting biological activities at small dose, ${ }^{[3]}$ or can find valuable applications in materials science. ${ }^{[4]}$ Another interest of this group is the lipophilicity induced in organic moieties. The recent determination of its Hansch parameter shows a value slightly lower than the parent $\mathrm{SCF}_{3}$ group and similar to the one of the $\mathrm{SF}_{5}$ group, another emerging group. ${ }^{[5]}$ Therefore, the development of new methods to incorporate the $\mathrm{SeCF}_{3}$ moiety directly into organic molecules is highly desirable.

To date, most of the available strategies to directly introduce a $\mathrm{SeCF}_{3}$ group are nucleophilic or electrophilic approaches (using either nucleophilic $\mathrm{MSeCF}_{3}$ reagents, $M=1 / 2 \mathrm{Hg}, \mathrm{Cu}, \mathrm{Me}_{4} \mathrm{~N}$, or electrophilic $\mathrm{XSeCF}_{3}$ reagents, $\mathrm{X}=\mathrm{SeCF}_{3}, \mathrm{Cl}$, Tosyl, Scheme 1a,b). ${ }^{[6,7]}$ Very recently, Billard, Tlili and co-workers reported the first radical trifluoromethylselenolation reaction under visible-light photoredox calatysis, using the electrophilic reagent $\mathbf{I}^{\left[{ }^{[8]}\right.}$ This radical process was notably applied to the efficient synthesis of trifluoromethylselenolated arenes from the corresponding diazonium salts (Scheme 1c). ${ }^{[\mathrm{a}]}$ However,

[a] A. De Zordo-Banliat, F. Bourdreux, Dr. G. Dagousset, Dr. B. Pégot, Dr. E. Magnier

Institut Lavoisier de Versailles, UMR 8180, Université de VersaillesSaint-Quentin 78035 Versailles Cedex, France,

http://www.ilv.uvsq.fr/

Fax: $(+) 33139254452$

[b] L. Barthélémy, Dr. B. Tuccio

Aix-Marseille Université-CNRS, Institut de Chimie Radicalaire, UMR 7273, F-13397 Marseille Cedex 20, France a) Nucleophilic trifluoromethylselenolation

$$
\begin{aligned}
& \mathrm{MSeCF}_{3} \stackrel{\text { "Electrophile" }}{\longrightarrow} \mathrm{R}-\mathrm{SeCF}_{3} \\
& M=1 / 2 \mathrm{Hg}, \mathrm{Cu}, \mathrm{Me}_{4} \mathrm{~N}
\end{aligned}
$$

b) Electrophilic trifluoromethylselenolation

$$
\begin{aligned}
& \mathrm{X}-\mathrm{SeCF}_{3} \stackrel{\text { "Nucleophile" }}{\longrightarrow} \mathrm{R}-\mathrm{SeCF}_{3} \\
& \mathrm{X}=\mathrm{SeCF}_{3}, \mathrm{Cl} \text {, Tosyl }
\end{aligned}
$$

c) Radical photoredox-mediated trifluoromethylselenolation

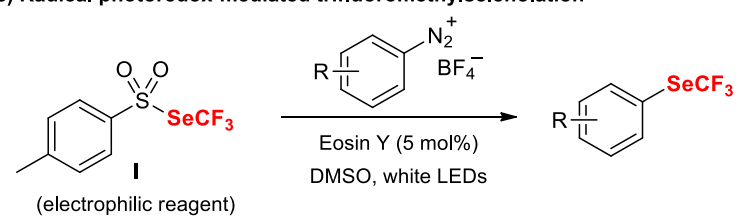

d) This work: radical C-H trifluoromethylselenolation of heteroarenes

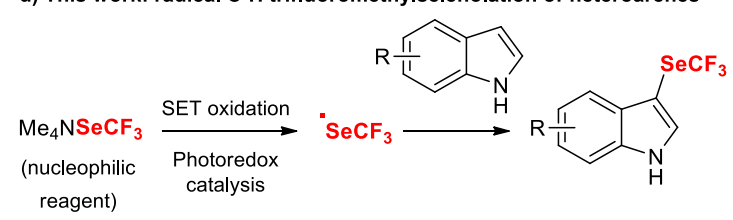

Scheme 1. The different strategies for the direct introduction of the $\mathrm{SeCF}_{3}$ moiety.

considering the low commercial availability of diazonium salts, a greener approach would consist in the direct $\mathrm{C}-\mathrm{H}$ trifluoromethylselenolation of non-prefunctionalized arenes. Based on our previous works on the photoredox-catalysed synthesis of fluorinated compounds, ${ }^{[9]}$ we anticipated that the $\cdot \mathrm{SeCF}_{3}$ radical could also be generated from a nucleophilic source of $\mathrm{SeCF}_{3}$ via a visible-light-induced SET (Single Electron Transfer) oxidation. This fluorinated radical would then easily react with aromatic substrates (Scheme 1d). We wish to report herein a new visible-light-promoted aerobic $\mathrm{C}-\mathrm{H}$ trifluoromethylselenolation of heteroarenes, which proceeds under very mild, metal-free and eco-friendly reaction conditions.

We focused our initial investigations on the trifluoromethylselenolation of indole (1a) with the easily accessible and air-stable $\mathrm{Me}_{4} \mathrm{NSeCF}_{3}$ reagent 2 (Table 1). ${ }^{[6 d]}$ We were pleased to see that the reaction using 2 mol\% of $\mathrm{Ru}(\mathrm{bpy})_{3}\left(\mathrm{PF}_{6}\right)_{2}$ (3a, bpy $=2,2^{\prime}$-bipyridine) as the photocatalyst with blue LEDs irradiation under air atmosphere furnished a high yield of the 3trifluoromethylselenolated indole $4 a(87 \%$, entry 1). A survey of organic dyes in place of $\mathrm{Ru}(\mathrm{bpy})_{3}\left(\mathrm{PF}_{6}\right)_{2}$ revealed that Eosin $Y(\mathbf{3 d})$ was the optimal organophotocatalyst for this transformation, affording an almost quantitative yield of 
Table 1. Survey of reaction conditions for the photocatalyzed trifluoromethylselenolation of indole $\mathbf{1 a}$.

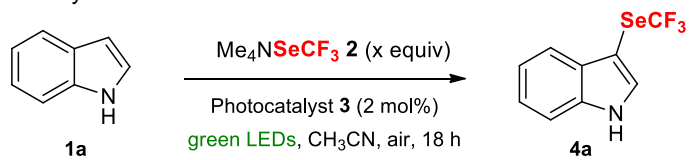

\begin{tabular}{cccc}
\hline Entry & $\mathrm{x}$ & Photoredox catalyst 3 & ${\text { Yield }[\%]^{[a, b]}}^{2}$ \\
\hline $1^{[\mathrm{c}]}$ & 2 & $\mathrm{Ru}(\mathrm{bpy})_{3}\left(\mathrm{PF}_{6}\right)_{2} \mathbf{3 a}$ & 87 \\
2 & 2 & Rhodamine B 3b & 35 \\
3 & 2 & Rose Bengal 3c & 34 \\
4 & 2 & Eosin Y 3d & $99(89)^{[\mathrm{d}]}$ \\
$5^{[\mathrm{e}]}$ & 2 & $\mathbf{3 d}$ & 48 \\
6 & 1.5 & $\mathbf{3 d}$ & 60 \\
$7^{[\mathrm{f}]}$ & 2 & $\mathbf{3 d}$ & 0 \\
$8^{[\mathrm{g}]}$ & 2 & $\mathbf{3 d}$ & 0 \\
9 & 2 & none & 7 \\
\hline
\end{tabular}

[a] General conditions: 1a $(0.20 \mathrm{mmol}), \mathbf{2}$ (x equiv), 3 (0.02 equiv) in MeCN (2 $\mathrm{mL}$ ) irradiated with green LEDs at RT for $18 \mathrm{~h}$. [b] Yields determined by ${ }^{19} \mathrm{~F}$ NMR spectroscopy using $\mathrm{PhOCF}_{3}$ as an internal standard. [c] Reaction performed with blue LEDs irradiation. [d] Yields referred to chromatographically pure product into brackets. [e] Reaction performed with 1 mol\% of 3d. [f] Reaction performed in the dark. [g] Reaction performed under argon atmosphere. 4a (entries 2-4). Attempts to use reduced amount of $\mathrm{SeCF}_{3}$ reagent or of the photocatalyst led to diminished yields (entries 5-6), and air, light and catalyst were all essential partners for the reaction to proceed (entries 7-9).

Having established the optimal reaction conditions, the scope of this novel photocatalysed trifluoromethylselenolation was next investigated and the results are summarised in Scheme 2. Pleasingly, a wide range of indole derivatives 1a-1s were smoothly trifluoromethylselenolated. The mild reaction conditions were compatible with a large array of electrondonating or -withdrawing functionalities at position 2, 4, 5 or 6 of the indole scaffold, including ethers, nitro, halogens, nitriles, esters, aldehydes, ketones and boronic esters. This process was fully regioselective in favour of the 3-position, and it is worth to note that no reaction took place in the case of 3-substituted indoles. Remarkably, this reaction was successfully broadened to other electron-rich heteroaromatic substrates: 7-azaindole (1t) and 4-azaindole (1u) were efficiently converted into the corresponding $\mathrm{SeCF}_{3}$-adducts $\mathbf{4 t - 4 u}$ in high yields, while functionalized pyrroles $\mathbf{1 v - 1 z}$ selectively afforded the corresponding 2-trifluoromethylselenolated pyrroles $\mathbf{4 v - 4 z}$, albeit in moderate yields.

In addition, this novel protocol was also optimized with the use of continuous-flow techniques, which are perfectly well adapted to photochemical transformations: indeed, the narrow PFA tubing (1.3 mm, PFA = perfluoroalkoxy) of the flow device allows for an optimal and homogeneous irradiation of the reaction mixture, heat and mass transfer characteristics are enhanced,<smiles>CCC(C)(C)c1c(C(F)(F)F)[nH]c(C(F)(F)F)c1C</smiles>

Scheme 2. Scope of the visible-light-mediated trifluoromethylselenolation of heteroarenes. General conditions: 1 (0.2 mmol), 2 (0.4 mmol), $3 \mathbf{d}(2 \mathrm{~mol} \%)$ in $2 \mathrm{~mL}$ of $\mathrm{MeCN}$ irradiated with green LEDs under air for $18 \mathrm{~h}$ at rt. Yields referred to chromatographically pure products, and yields into brackets were determined by ${ }^{19} \mathrm{~F}$ NMR spectroscopy using $\mathrm{PhOCF}_{3}$ as internal standard. [a] $1 \mathrm{mmol}$ scale. [b] $36 \mathrm{~h}$ of irradiation. 
and scale-up experiments are facilitated under safer reaction conditions ${ }^{[10]}$ In order to reach complete conversion of indole $\mathbf{1 a}$, slight modifications of the reaction conditions were made. The concentration of the reaction was decreased to $0.033 \mathrm{M}$ to achieve complete dissolution, and air was replaced by $\mathrm{O}_{2}$ (see $\mathrm{SI}$ for more details). With these optimal conditions, the residence time could be decreased to only 50 min of irradiation, and the expected $\mathrm{SeCF}_{3}$ product $4 \mathrm{a}$ was obtained in $81 \%$ yield. Furthermore, the same experiment was performed on a larger scale without any significant loss of the yield $(1 \mathrm{mmol}$, Scheme $3)$.

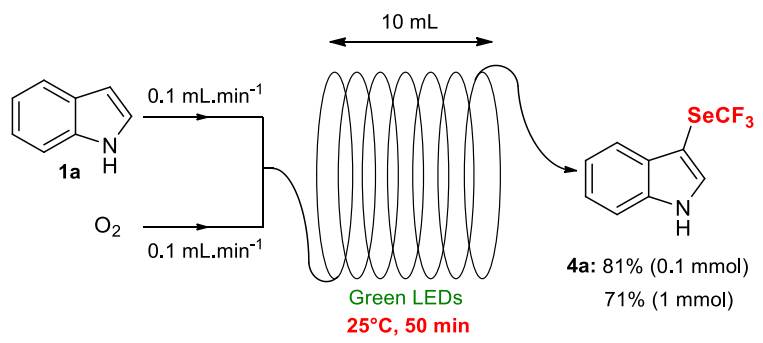

Scheme 3. Synthesis of 3-(trifluoromethylselanyl)indole (4a) using continuous flow.

We then decided to investigate the mechanism of this transformation. The fact that both Eosin $Y$ and continuous irradiation were needed for the reaction to proceed (see Table 1 and the Supporting information for light on/off experiments) suggested that a radical pathway was involved. To verify this hypothesis, some spin trapping/electron paramagnetic resonance (ST/EPR) experiments were carried out with 2methylnitrosopropane (MNP) as the spin trap. In a first step, irradiating the radical source $\mathrm{Me}_{4} \mathrm{NSeCF}_{3} 2$ in presence of Eosin $Y \mathbf{3 d}$ and MNP led to record a very intense three line EPR spectrum $\left(\mathrm{a}_{\mathrm{N}}=15.7 \mathrm{G}\right.$, spectrum I, Scheme $\left.4 \mathrm{a}\right)$. Since blank tests performed in the absence of either $\mathrm{Me}_{4} \mathrm{NSeCF}_{3} 2$ or of Eosin $Y$ 3d never yielded any signal, spectrum I could be assigned to the spin adduct formed after trapping the radical - $\mathrm{SeCF}_{3}$, i.e. $\mathrm{MNP}-\mathrm{SeCF}_{3}$, the satellite lines being due to a hyperfine coupling with ${ }^{13} \mathrm{C}$ in $\beta$-position (natural abundance, $a_{13 c}=4.2 \mathrm{G}$ ). The generation of $\cdot \mathrm{SeCF}_{3}$ was further confirmed by ST/EPR experiments performed with the nitrone spin trap DMPO (see ESI). In a second step, additional spin trapping experiments were performed in the presence of excess of indole 1a, added to the medium containing reagent $\mathbf{2}, \mathrm{MNP}$ and photocatalyst $\mathbf{3} \mathbf{d}$. The EPR spectrum II given in Scheme 4 a was thus recorded. Its analysis revealed the presence of two spin adducts, the minor one $\left(10 \%, a_{N}=15.7 \mathrm{G}\right)$ corresponding to $\mathrm{MNP}_{-} \mathrm{SeCF}_{3}$. The major compound $(90 \%)$ shows a more complex signal due to hyperfine couplings with the nitroxide nitrogen $\left(\mathrm{a}_{\mathrm{N}}=14.5 \mathrm{G}\right)$, but also with one hydrogen $\left(\mathrm{a}_{\mathrm{H} \beta}=2.7 \mathrm{G}\right)$ and one nitrogen $\left(\mathrm{a}_{\mathrm{N} \beta}=1.8\right.$ $\mathrm{G})$ nuclei, both in $\beta$ position towards the nitroxide function. This is perfectly consistent with adduct MNP-B obtained after trapping of the carbon-centered radical $\mathbf{B}$ coming from the addition of $\cdot \mathrm{SeCF}_{3}$ onto indole (Scheme $4 \mathrm{~b}$ ). It is worth noting that, to the best of our knowledge, such $\alpha$-amino radical $\mathbf{B}$ has

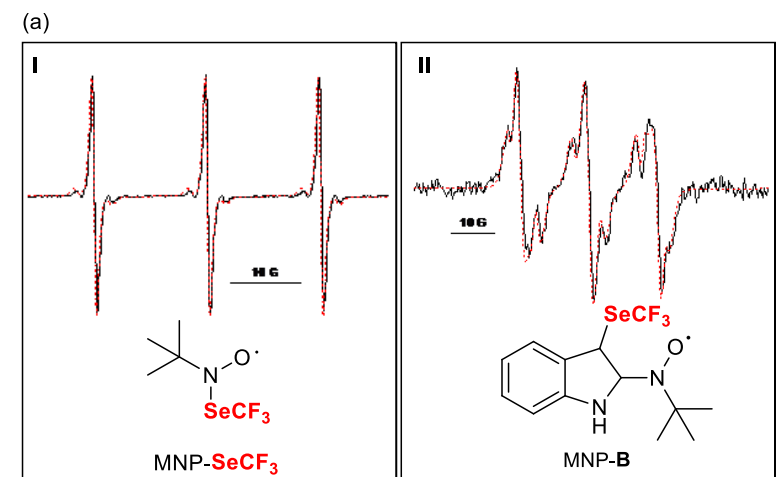

(b)
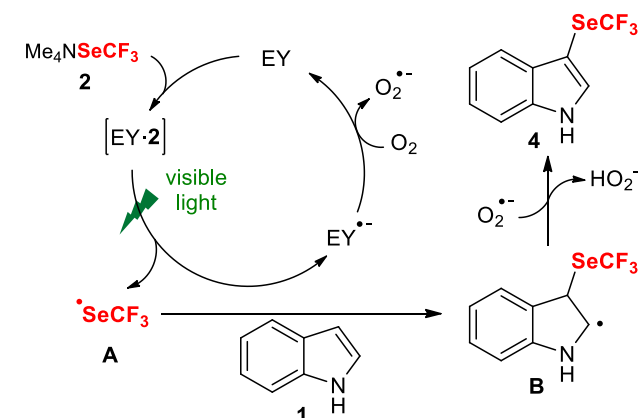

Scheme 4. (a) EPR spectra obtained using MNP as the spin trap (red dotted lines correspond to the calculated spectra). For experimental details, see the SI. (b) Proposed mechanism.

never been characterized in other similar radical $\mathrm{C}-\mathrm{H}$ functionalizations of indoles.

In addition, redox potentials of indole $\mathbf{1 a}$ and $\mathrm{Me}_{4} \mathrm{NSeCF}_{3} \mathbf{2}$ were measured by cyclic voltametry (see the Supporting Information). The respective values of oxidation potential $\left(\mathrm{E}_{1 \mathrm{a}}=+1.46 \mathrm{~V}\right.$ and $\mathrm{E}_{2}=+0.72 \mathrm{~V}$ vs. SCE) clearly showed that the oxidation of 2 by the excited state $E Y^{*}$ of $\mathbf{3 d}\left(E_{E Y^{*} / E Y .-}=+0.83 \mathrm{~V} \text { vs. SCE }\right)^{[11]}$ is thermodynamically feasible, while oxidation of $\mathbf{1 a}$ by $E Y^{*}$ is a thermodynamically unfavourable process. Furthermore, luminescence quenching experiments were performed. No quench of the excited state $E Y^{*}$ of $\mathbf{3 d}$ was observed with indole $\mathbf{1 a}$, which also invalidated the direct oxidation of $\mathbf{1 a}$ by $E Y^{*}$. We also monitored the UV-Vis absorbance of EY in the presence of 1a or 2. While no change was noted with 1a, a small hypsochromic shift (from $538 \mathrm{~nm}$ to $527 \mathrm{~nm}$ ) was observed when increasing concentrations of $\mathrm{Me}_{4} \mathrm{NSeCF}_{3} 2$ were added. This observation might suggest the formation of a ground-state complex between EY and 2, which was further corroborated by NMR experiments (see the Supporting Information).

Moreover, the measurement of the quantum yield of this reaction (0.48, see the Supporting Information for more details) suggested that a radical chain mechanism is not the major operative pathway of this transformation.

On the basis of all these studies, a plausible mechanism is depicted in Scheme 4b. Eosin $Y$ would first associate with reagent 2, leading to a ground-state complex [EY.2]. Then, irradiation of this complex with green LEDs would give rise to the . $\mathrm{SeCF}_{3}$ radical $\mathbf{A}$, which would add onto indole $\mathbf{1}$, leading to radical intermediate $\mathbf{B}$. Both radicals $\mathbf{A}$ and $\mathbf{B}$ were clearly 
identified by ST/EPR experiments. Then radical B would be easily oxidized with concurrent loss of a proton, affording the desired 3-trifluoromethylselenolated indole $\mathbf{4}$. It is also worth noting that no dimeric species $\mathrm{CF}_{3} \mathrm{SeSeCF}_{3}$ was observed during the reaction, even when using in operando ${ }^{19} \mathrm{~F}$ NMR spectroscopy. However, a polar mechanism involving this dimer, which would account for the observed C-3 regioselectivity, cannot be completely ruled out.

In conclusion, we have developed a new visible-light mediated aerobic $\mathrm{C}-\mathrm{H}$ trifluoromethylselenolation of heteroarenes using the air-stable and readily accessible nucleophilic reagent $\mathrm{Me}_{4} \mathrm{NSeCF}_{3}$. This atom-economical methodology operates under very mild and metal-free conditions, and has been successfully applied to a wide range of indoles, azaindoles, and pyrroles bearing various functional groups, either in batch or in flow. Extension of this work to other radical trifluoromethylselenolation reactions is currently underway in our laboratory and will be reported in due course.

\section{Experimental Section}

General procedure: In a test tube were added the indole $1(0.2 \mathrm{mmol}, 1$ equiv), Eosin Y 3d (0.004 mmol, $2 \mathrm{~mol} \%$ ) and $\mathrm{Me}_{4} \mathrm{NSeCF}_{3} 2(0.4 \mathrm{mmol}$, 2 equiv.). MeCN ( $2 \mathrm{~mL}$ ) was added and the solution was stirred at room temperature under green LED irradiation for $18 \mathrm{~h}$ opened to air atmosphere. The crude was then purified by preparative TLC to afford the corresponding pure product.

\section{Acknowledgements}

AZB thanks LabEx Charmmmat for a Master's student fellowship. BT acknowledges the CNRS research infrastructure RENARD for access to the EPR facilities and the NIEHS for providing free the WINSIM software used to simulate the EPR spectra. LabEx Charmmmat is gratefully acknowledged for the funding of the continuous flow device. Agence Nationale de la Recherche (ANR) is warmly acknowledged for funding (ANR 18-CE07-0039-01).

Keywords: selenium • fluorine $\cdot$ photoredox catalysis • trifluoromethylselenation $\bullet$ indoles

[1] a) P. Kirsch in Modern Fluoroorganic Chemistry: Synthesis, Reactivity, Applications, $2^{\text {nd }}$, Completely Revised and Enlarged edition, Wiley: New-York, 2013; b) K. Müller, C. Faeh, F. Diederich, Science 2007, 317,1881 ; c) Bioorganic and Medicinal Chemistry of Fluorine (Eds.: J.P. Begue, D. Bonnet-Delpon), Wiley, Hoboken, 2008; d) J. Wang, M. Sanchez-Rosello, J. L. Acena, C. del Pozo, A. E. Sorochinsky, S. Fustero, V. A. Soloshonok, H. Liu, Chem. Rev. 2014, 114, 2432.

[2] Selected reviews: a) A. Tlili, F. Toulgoat, T. Billard, Angew. Chem. 2016, 128, 11900; Angew. Chem. Int. Ed. 2016, 55, 11726; b) T. Besset, P.
Jubault, X. Pannecoucke, T. Poisson, Org. Chem. Front. 2016, 3, 1004 c) A. Tlili, E. Ismalaj, Q. Glenadel, C. Ghiazza, T. Billard Chem. Eur. J. 2018, 24, 3659; d) C. Ghiazza, T. Billard, A. Tlili, Chem. Eur. J. 2019, 25,6482 .

[3] a) A. Krief, L. Hevesi in Organoselenium Chemistry I. Functional GroupTransformations; Springer: Berlin, 1988; b) H. E. Ganther, Carcinogenesis 1999, 20, 1657; c) R. Naithani, Mini-Rev. Med. Chem. 2008, 8, 657 ; d) L. V. Papp, A. Holmgren, K. K. Khanna, Antioxid. Redox Signaling 2010, 12,793; e) M. C. Ledesma, B. Jung-Hynes, T. L. Schmit, R. Kumar, H. Mukhtar, N. Ahmad, Mol. Med. 2011, 17, 134; f) R. Mousa, R. N. Dardashti, N. Metanis, Angew. Chem. 2017, 129, 16027; Angew. Chem. Int. Ed. 2017, 56, 15818.

[4] L. V. Romashov, V. P. Ananikov, Chem. Eur. J. 2013, 19, 17640.

[5] Q. Glenadel, E. Ismalaj, T. Billard, Eur. J. Org. Chem. 2017, 530.

[6] Selected trifluoromethylselenolations with nucleophilic $\mathrm{SeCF}_{3}$ reagents: a) N. V. Kondratenko, A. A. Kolomeytsev, V. I. Popov, L. M. Yagupolskii, Synthesis 1985, 667; b) C. Chen, L. Ouyang, Q. Lin, Y. Liu, C. Hou, Y. Yuan, Z. Weng, Chem. Eur. J. 2014, 20, 657; c) Y. Wang, Y.You, Z. Weng, Org. Chem. Front. 2015, 2, 574; d) Q. Lefebvre, R. Pluta, M. Rueping, Chem. Commun. 2015, 51, 4394; e) M. Aufiero, T. Sperger, A. S.-K. Tsang, F. Schoenebeck, Angew. Chem. 2015, 127, 10462; Angew. Chem. Int. Ed. 2015, 54, 10322; f) C. Matheis, V. Wagner, L. J. Goossen, Chem. Eur. J. 2016, 22, 7; g) C. Matheis, T. Krause, V. Bragoni, L. J. Goossen, Chem. Eur. J. 2016, 22, 12270; h) J.-B. Han, T. Dong, D. A. Vicic, C.-P. Zhang, Org. Lett. 2017, 19, 3919; i) T. Dong, J. He, Z.-H. Li, C.-P. Zhang, ACS Sustain. Chem. Eng. 2018, 6, 1327; j) Q.-Y. Han, C.-L. Zhao, T. Dong, J. Shi, K.-L. Tan, C.-P. Zhang, Org Chem. Front. 2019, 10.1039/C9Q000631A.

[7] Selected trifluoromethylselenolations with electrophilic $\mathrm{SeCF}_{3}$ reagents: a) E. Magnier, C. Wakselman, Collect. Czech. Chem. Commun. 2002, 67, 1262; b) Q. Glenadel, E. Ismalaj, T. Billard, J. Org. Chem. 2016, 81, 8268; c) C. Ghiazza, Q. Glenadel, A. Tlili, T. Billard, Eur. J. Org. Chem. 2017, 3812; d) C. Ghiazza, A. Tlili, T. Billard, Eur. J. Org. Chem. 2018 3680; e) S. Dix, M. Jakob, M. N. Hopkinson, Chem. Eur. J. 2019, 25, 7635.

[8] a) C. Ghiazza, V. Debrauwer, C. Monnereau, L. Khrouz, M. Médebielle, T. Billard, A. Tlili, Angew. Chem. 2018, 130, 11955; Angew. Chem. Int Ed. 2018, 57, 11781; b) C. Ghiazza, L. Khrouz, C. Monnereau, T. Billard, A. Tlili, Chem. Commun. 2018, 54, 9909; c) C. Ghiazza, C Monnereau, L. Khrouz, M. Médebielle, T. Billard, A. Tlili, Synlett 2019, 30, 777 .

[9] a) A. Carboni, G. Dagousset, E. Magnier, G. Masson, Org. Lett. 2014 16, 1240; b) A. Carboni, G. Dagousset, E. Magnier, G. Masson, Synthesis 2015, 47, 2439; c) L. Jarrige, A. Carboni, G. Dagousset, G. Levitre, E. Magnier, G. Masson Org. Lett. 2016, 18, 2906; d) G. Dagousset, C. Simon, E. Anselmi, B. Tuccio, T. Billard, E. Magnier, Chem. Eur. J. 2017, 23, 4282; e) M. Daniel, G. Dagousset, P. Diter, P.A. Klein, B. Tuccio, A.-M. Goncalves, G. Masson, E. Magnier, Angew. Chem. 2017, 129, 4055; Angew. Chem. Int. Ed. 2017, 56, 3997; f) G. Levitre, G. Dagousset, E. Anselmi, B. Tuccio, E. Magnier, G. Masson, Org. Lett. 2019, 21, 6005.

[10] Selected reviews: a) J. P. Knowles, L. D. Elliott, K. I. Booker-Milburn, Beilstein J. Org. Chem. 2012, 8, 2025; b) Y. Su, N. J. W. Straathof, V. Hessel, T. Noël, Chem. Eur. J. 2014, 20, 10562; c) Z. J. Garlets, J. D. Nguyen, C. R. J. Stephenson, Isr. J. Chem. 2014, 54, 351; d) M. B. Plutschack, C. A. Correia, P. H. Seeberger, K. Gilmore, Top. Organomet. Chem. 2016, 57, 43; e) D. Cambié, C. Bottecchia, N. J. W. Straathof, V. Hessel, T. Noël, Chem. Rev. 2016, 116, 10276

[11] D. Prasad Hari, B. König, Chem. Commun. 2014, 50, 6688 


\section{COMMUNICATION}

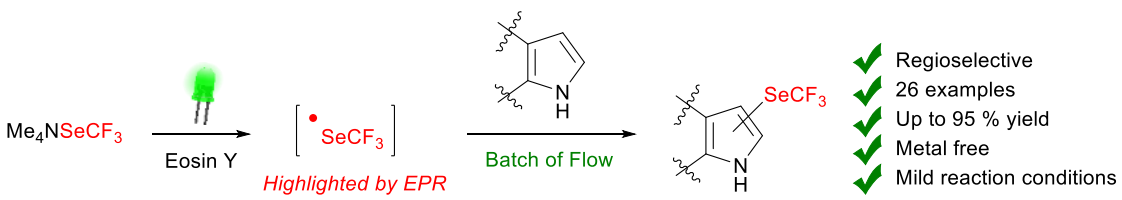

Green trifluoromethylselenolation : a radical pathway, demonstrated by physicochemical studies, allows the regioselective introduction of the $\mathrm{SeCF}_{3}$ group on indoles and other heterocycles. This metal free photoredox pathway occurs under irradiation with green led on batch and flow conditions.
Arnaud De Zordo-Banliat, ${ }^{[a]}$ Lucas Barthélémy, ${ }^{[b]}$ Flavien Bourdreux, ${ }^{[a]}$ Béatrice Tuccio, ${ }^{[b]}$ Guillaume Dagousset, ${ }^{*[a]}$ Bruce Pégot, ${ }^{*[a]}$ and Emmanuel Magnier ${ }^{*}[a]$

Page No. - Page No.

Visible-Light-Induced Metal-Free Trifluoromethylselenolation of Electron-Rich Heteroarenes using the Nucleophilic $\left[\mathrm{Me}_{4} \mathrm{~N}\right]\left[\mathrm{SeCF}_{3}\right]$ Reagent 